\section{Contributors}

Jeffrey Aronson is editor of the British Journal of Clinical Pharmacology. Here he is on patients taking their drugs:

'Compliance, adherence, concordance. These terms do not mean the same thing at all. "Compliance" is used to refer to whether a patient takes or doesn't take a prescribed medicine. It carries overtones of paternalism on the part of the prescriber. "Adherence" means much the same thing, but without the paternalistic overtones, and is the term that I prefer. "Concordance" refers to a mythical state in which the prescriber and doctor have a negotiation and come to an agreement about what the treatment should be. In my view, the doctor should advise the patient about the different options and about which of them is/are preferred; the patient should then decide what to do. A belief that some sort of negotiation during this process is either possible or desirable is misguided. If any negotiation, in the true sense of the word ("A discussion or process of treaty with another (or others) aimed at reaching an agreement about a particular issue, problem, etc." OED), takes place (as does happen) it will inevitably mitigate the value of the treatment. This is because, if one assumes that the doctor advises the best course of action, anything different from that will be less than best. Of course, there are sometimes alternatives that may be equally good, but the patient can then choose, and negotiation is not necessary. I recently wrote about these three terms (Br J Clin Pharmacol 2007; 63: 383-384) and aroused the wrath of the concordance hornets. I replied $(\mathrm{Br} J$ Clin Pharmacol 2007; 64: 711-713), suggesting that we should abandon the term "concordance". I have heard no more.

jeffrey.aronson@clinpharm.ox.ac.uk

Edzard Ernst is Professor of Complementary Medicine at the Peninsula Medical School, University of Exeter.

eernst@pms.ac.uk

Jane Moore is a GP in Leatherhead, Kent. She is presently travelling in New Zealand.

moore.jane@doctors.org.uk

Jane Roberts is a GP in Easington in the northeast of England. She is a Clinical Senior Lecturer in general practice at the University of Sunderland.

jane.roberts@sunderland.ac.uk

\title{
Fellow feeling
}

'I can definitely hear something.' $\mathrm{He}$ takes the stethoscope out of his ears and smiles encouragingly. Peter is here to resolve crisis number one.

He motions to me to have a listen too, to hear what he hears. Somewhat selfconsciously, I have a go, kneeling quietly and listening hard. I feel like a young student again, my head full of internal dialogue when I want it to be still. There is a buzzing somewhere, and I hear a jet swoop by overhead, but it is not easy to convince myself that I am hearing what he hears. My knuckles crackle quietly as I try to hold the stethoscope even more gently. Eventually I realise I have listened for long enough and straighten up again. $\mathrm{He}$, it seems, has shifted his attention and started to drift away by now.

I call out to his retreating frame. 'I still can't convince myself I can hear anything you know.' He hears me and stops, turning.

He beams at me, his face full of friendly understanding. 'I think it was the fish tank pump we were hearing there.'

'Ah yes, of course,' I mutter sheepishly: how stupid of me not to think of that. Leaks in central heating pipes may not always be so easy to diagnose without a wet patch to go by but auscultation of the pipes now seems a little bit more complex than it did. I follow our plumber to the next room, feeling part dumb student, part fellow listening professional.

Meanwhile, outside, it seems the car has a flat battery: crisis number two. Sparky comes and jump starts it only to ring up from his garage a short while later to explain that when he took the key out the engine didn't stop.

'It definitely should not be doing that,' I agree, secure in my understanding of this part of How Cars Work.

'No,' says Sparky, 'I wondered whether the problem was the electronic engine management system, but now I think it must be a malfunction in the ignition switch.'

I am filled with that sense of camaraderie for a fellow professional again. 'Yes,' I agree knowledgeably. I referred someone for surgery only this morning who had a faulty ignition switch, I think to myself. But I know that I cannot tell of this any more than Sparky can tell others of my predicament: we each must carry the burden of our knowledge in silence.

My phone rings. This is crisis number three. A momentary wave of relief sweeps through my mind - at least I know now what it is going to be. Wendy tells me there is an urgent house call. Fortunately it is close enough to walk there en route back to the surgery.

I walk straight in when I get to $\mathrm{Ma}$ Diggins' house: she and I know each other well. She smokes, as did her husband until his untimely death, and a haze pervades the place. We have talked about her stopping many times and no longer bother, concentrating instead on subjects that lack controversy, like the clarity of the air outside.

'Oh hello doc,' she greets me with fake warmth from the security of her usual chair. She makes no move at all, simply waiting for me to perform my usual routine.

I grunt some kind of equally habitual reply, reaching into my bag for a stethoscope. As I pull it out I notice the fish tank behind her: funny I had not noticed that before. There is a patch of wet phlegm on her jumper.

'Chest infection?' I ask rhetorically, stowing my stethoscope again.

'Yes, I'm quite sure,' she responds, breathing heavily to help demonstrate.

'Here are some more antibiotics then.' And I just hand them over for once, no arguments. 'Get that into your radiator,' I even joke, though I can tell that leaves her utterly confused.

DOI: 10.3399/bjgp08X279634 